Association for Information Systems

AIS Electronic Library (AISeL)

Wirtschaftsinformatik 2021 Proceedings

Track 2: General Track - Innovative, emerging and interdisciplinary topics

\title{
Many Hands Make Light Work: The Influence of Organizational Culture on Idea Platform Implementation
}

Timo Koppe

Technische Universität Darmstadt

Follow this and additional works at: https://aisel.aisnet.org/wi2021

Koppe, Timo, "Many Hands Make Light Work: The Influence of Organizational Culture on Idea Platform Implementation" (2021). Wirtschaftsinformatik 2021 Proceedings. 5.

https://aisel.aisnet.org/wi2021/YGeneralTrack/Track02/5

This material is brought to you by the Wirtschaftsinformatik at AIS Electronic Library (AISeL). It has been accepted for inclusion in Wirtschaftsinformatik 2021 Proceedings by an authorized administrator of AIS Electronic Library (AISeL). For more information, please contact elibrary@aisnet.org. 


\title{
Many Hands Make Light Work: The Influence of Organizational Culture on Idea Platform Implementation
}

\author{
Timo Koppe \\ Technical University of Darmstadt, Software \& Digital Business, Darmstadt, Germany \\ koppe@is.tu-darmstadt.de
}

\begin{abstract}
Recent years have seen an increasing emphasis on IT-enabled crowdsourcing for innovation in organizations. However, information systems literature has so far paid little attention to the role of information systems in idea crowdsourcing, including its relation to organizational culture. To address this research gap, we conducted a quantitative study with IT and innovation managers from various organizations $(\mathrm{N}=81)$ to explore whether culture influences the implementation of idea platforms. Our key findings show that idea platform implementation is facilitated by a culture that emphasizes policies, procedures, as well as information management (hierarchical culture). Although a culture of creativity should be stimulated in the front-end of innovation, the results indicate that idea platforms are predominantly used in conjunction with a strong internal focus and set of values.
\end{abstract}

Keywords: Crowdsourcing, organizational culture, idea platform, innovation, quantitative study.

\section{Introduction}

The emergence and diffusion of digital technologies confront organizations with significant pressure to innovate and renew themselves. For this purpose, organizations are exploring new ways to identify promising opportunities and examine how their organizational knowledge can lead to the introduction of innovation [1, 2], especially since innovation processes are becoming more distributed and open [3]. In this regard, organizations can leverage a multitude of methods and measures of innovation management that have been established in recent years. They use open innovation, cocreation, and crowdsourcing to break out of their traditional innovation process [4].

Especially crowdsourcing has increased popularity as a method for gathering ideas and innovation [5, 6]. Simultaneously, the rapid development of social information technologies and platforms provide new ways to enable crowdsourcing. These technologies facilitate cooperation and collaboration between users, exchange of insights and experiences, build social networks [7], connect intelligence, and thus access to the "wisdom of the crowds" [8]. In this paper, we refer to idea platforms as specific crowdsourcing IT tools for collecting, discussing, enhancing, and evaluating ideas [5]. Thereby, information systems (IS) play a huge role in enabling and shaping 
crowdsourcing for innovation and will become more relevant in the future since, e.g., ideas are valuable data [6]. However, IS literature has so far paid little attention to the role of IS in idea crowdsourcing [5, 9]. Instead, prior management research has largely dealt with the optimal design of idea competitions, i.e., the motivation of employees $[10,11]$, characteristics of idea authors $[12,13]$, and the role of community functions $[14,15]$. Still, many IT-based idea competitions fail to achieve active participation [16]. Simula and Vuori [6] state that organizational culture (OC) can be seen as an issue when motivating participants to submit their ideas to IT platforms. At the same time, internal idea crowdsourcing can also support OC [6]. Prior research indicates that IT tools, i.e., idea platforms, must be in line with complementary non-IT resources, like culture, to leverage value for the business [17]. For example, idea competitions need to emphasize a climate of cooperation and competition at the same time [18]. Against this background, we examine the influence of $\mathrm{OC}$ on the current status of idea platform implementation. For this purpose, we use the competing values framework (CVF) to measure OC, which is common and frequently used in this context [19-22]. Our research question is: How do the organizational culture dimensions influence idea platform implementation? To answer the research question, we conducted a quantitative study with IT and innovation managers from various organizations $(\mathrm{N}=81)$. In this context, we also examined the planned versus the actual implementation of idea platforms in an additional part to inspire theory building [23]. Our research goal is to indicate further criteria that influence the value contribution of idea platforms in organizations.

The remainder of this paper is structured as follows. After describing on the theoretical background and research design, we analyze the relationship between organizational culture and idea platform as well as differences in the planning and actual implementation of idea platforms. Finally, we discuss theoretical and practical implications as well as limitations and further research based on the findings of the empirical analysis.

\section{Theoretical Background}

\subsection{IT-enabled Crowdsourcing for Innovation}

The first phase of an organization's innovation process comprises the activities of generating and selecting ideas. This phase is referred to as the front-end of innovation or as the "fuzzy" front-end. It is described as informal, knowledge-intensive, and irregular [24]. These characteristics make it particularly difficult to manage this phase. This is also due to the fact that innovation management faces the challenge of creating a balance between a context of supporting and stimulating as well as orientation and focus [25]. Support and stimulation refer to creating a culture of creativity that enables employees and external users to increase the number and novelty of ideas. Simultaneously, the number of ideas is supposed to be reduced through orientation and focus to enhance quality and strategic direction [24]. Relevant ideas do not only emerge within the organization but can also be developed with the concept open innovation. 
This approach enables knowledge across organization boundaries and identifies and captures external knowledge to support the internal innovation process [26]. The inclusion of external sources of innovation has several advantages, e.g., it gives organizations access to distant knowledge that is far from an organization's current knowledge base [27]. A popular mechanism of gaining access to little explored and a richly heterogeneous pool of knowledge through online infrastructure is called crowdsourcing [28]. Crowdsourcing refers to the outsourcing of a variety of tasks [29]. In crowdsourcing, an open call is used to address a "crowd" and, thus, a group of individuals. Afuah and Tucci [27] distinguish two forms of crowdsourcing. First, in the competition-based approach, each individual chooses to work on their own solution to the problem. The best solution is selected as the winning solution. Second, in the collaboration-based approach, members of the crowd decide whether they want to collaborate on solving the problem. The result is a common solution of the crowd.

Idea crowdsourcing can be implemented in different formats and is often named differently: Idea competitions, challenges, contests, and tournaments. Members of the crowd can be, e.g., customers, partners, or employees [30]. Beyond that a distinction is made between design dimensions, such as task/topic specificity, target group, contest period, reward/motivation, or evaluation [31]. In this context, the task of an IT-enabled idea platform is to support the various formats and processes through its functionalities. Due to the diversity and the different naming conventions, we broadly refer to idea platforms as an online IT tool for collecting, discussing, enhancing, and evaluating ideas.

\subsection{Organizational Culture}

According to Hofstede and Hofstede [32], organizational culture is "the collective programming of the mind which distinguishes the members of one group or category of people from another." OC affects all areas of a company and has far-reaching consequences [33]. In particular, it influences the attitude of employees, e.g., job satisfaction [34], the operational performance of organizations, e.g., innovative strength [35], and the financial performance of organizations, e.g., profitability [36]. At the same time, the OC has an integration function for the employees of a company by conveying cohesion and a common identity. Recognized behavior patterns influence the behavior of employees and, thus, also their innovative behavior [37].

Although the $\mathrm{OC}$ is difficult to influence, management can still actively influence it and create the conditions for an innovation-friendly culture. By consistently participating in innovation projects and supporting employees, organizations can ensure that all employees have a positive experience with innovation. According to the basic assumptions of the OC, these experiences are condensed into a common, fundamental innovation image among the employees [37]. To achieve the goal of an innovation-conscious company, Hauschildt et al. [37] recommends to break down bureaucracy and to use innovation-promoting elements. This includes, among other things, promoting cooperation between different business functions and, in some cases, different business units [38]. 
An understanding of OC is also essential for IS research, as it can influence the successful implementation and use of IS. For example, culture plays a role in management processes that directly or indirectly impacts information technology [39]. Furthermore, introducing IT often encounters cultural resistance [40]. For these reasons, extensive literature on the relationship between IT and culture was produced, which Leidner and Kayworth [39] examined and synthesized. They identified two relevant topics in IT cultural research:

1. Culture and IS Development - The core of this topic is how culture influences the design of IS. It has been shown that in a culture where uncertainty is avoided, project risks are perceived differently and are more likely to be abandoned. It is also advantageous if the values of the OC match the values of the information system to be developed.

2. Culture, IT Adoption, and Diffusion - The core of this topic is whether culture influences the adoption and diffusion of IT. The dominant idea is that uncertainty avoidance plays a significant role in deciding how groups adopt and disseminate information and communication technologies. Most studies conclude that those who avoid uncertainty tend to adapt more slowly to new information technologies.

\section{Research Model}

To investigate the cultural factors affecting the implementation of an IT-enabled idea platform, we have oriented to the procedure of Ruppel and Harrington [41], which contributes to the topic 'Culture, IT Adoption, and Diffusion'. In their study, they examined the relationship between $\mathrm{OC}$ and intranet implementation in organizations. As a result, the acceptance of intranets is much more likely if there is a development culture. Ruppel and Harrington's study is based on the Competing Values Framework (CVF) [20] and was extended by them to include the ethical dimension. In research, the CVF is widely used to conceptualize OC $[19,20]$ and to investigate the relationships and effects of OC [21, 22]. The CVF distinguishes four types of OC based on two dimensions. The first dimension represents the degree to which the company's focus is internal or external. The internal focus emphasizes the integration and maintenance of the socio-technical system, while the external focus is on competition and interaction with the organizational environment. The second dimension refers to the differences between change and stability, with change focused on flexibility and spontaneity, while stability focuses on control, continuity and, order [20]. The resulting four types of OC are called group, development, rational, and hierarchical culture [19].

\subsection{Hypothesis Development}

Organizations with a developmental culture value flexibility and have an external focus. They are therefore not oriented towards their own company, but towards the market and the company's environment. The core of the development culture refers to growth, creativity, and continuous adaptation to external requirements, which are strongly market- and environment-related. Management believes in survival and growth through 
innovation $[42,43]$. Hence, it can be assumed that organizations with this culture know the advantages of idea platforms and are prepared to use them for themselves to remain competitive: H1 - There is a positive correlation between development culture and the implementation of idea platforms.

A company with a rational culture has a strong external focus and a focus on control. The main management activities are focused on maximizing profit through planning, control, and goal setting. By emphasizing order and stability, control structures with varying degrees of formalization and centralization are created to deal with contextual factors such as company size and environmental uncertainty [41]. Organizations with this culture focus primarily on competition and the optimization of their operations. We can assume that organizations with a rational culture will quickly become aware of the introduction of idea platforms through their external focus, but that the desire for order can stifle innovation. Since these effects are likely to balance each other out, we do not expect any significant influence of rational culture on the implementation of idea platforms: H2 - There is no correlation between rational culture and the implementation of idea platforms.

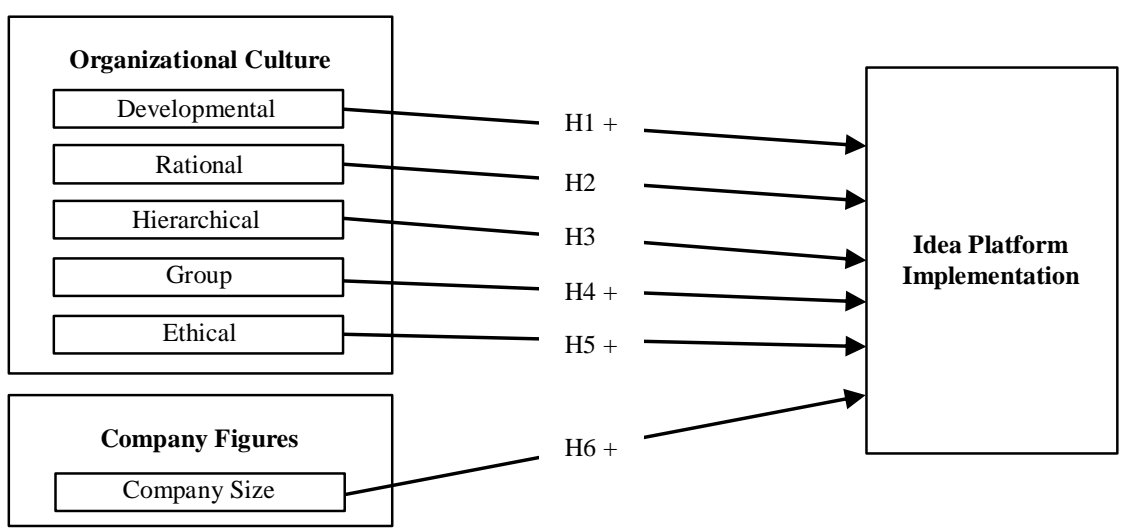

Figure 1.The Theoretical Model

In a hierarchical culture, the corporate environment is not seen as an essential factor. Management's interest focuses on measurement, documentation, and information management. The focus of these organizations is on control. Idea platforms can support an internal use in defined user groups as well as the implementation of clear processes for the idea process [44]. Idea platforms can also support the collection of ideas for continuous improvements and suggestions. However, the success of an idea platform in the innovation Front-end is supported by a creative and encouraging culture $[18,37]$. In contrast, a hierarchical culture focuses on internal orientation and order. Therefore, we assume that the effects are likely to balance each other out: H3 - There is no correlation between hierarchical culture and the implementation of idea platforms.

In a group culture, maintaining the company and its human resources is critical, with a focus on cohesive relationships, individual engagement and participation. While this culture is internally focused, it also values flexibility. Managers encourage dialogue, 
participation, and training of employees to achieve this goal. As they value employee participation, we believe idea platforms are an appropriate tool for organizations with a strong group culture. Idea platforms collect ideas by single employees as well as by groups, respectively [45]. Besides, idea platforms can support various social and community functions, which make idea competitions even more successful [14, 46, 47]. $\mathrm{H} 4$ - There is a positive correlation between group culture and the implementation of idea platforms.

Ethical culture reflects trust and an ethical working environment. Ruppel and Harrington expend the Competing Values Framework by this dimension since the CVF does not include specific measures for trust and an ethical work environment. Following them, there is no exchange of knowledge without a climate of trust $[48,49]$. Therefore, our assumption is H5 - There is a positive correlation between ethical culture and the implementation of idea platforms.

Finally, we believe that idea platforms are used independently of corporate industries because, the overall pressure to innovate in the economy has increased. However, we also believe the challenge to manage ideation initiatives increases with the company size. This would confirm other studies that report that web-based ideation systems are used especially within large organizations $[15,44,50]$. H6 - There is a positive correlation between company size and the implementation of idea platforms

\subsection{Data Collection, Research Design and Measurements}

We chose an online survey as the instrument for collecting the data for our study. Prior studies on organizational culture indicate that questionnaires are a reliable and wellestablished method for this kind of study [41]. In addition, the degree of anonymity in online questionnaires is perceived as very high, which tends to lead to greater openness and less often to social desirability bias [51]. When selecting participants for the study via social business networks, we considered three criteria. First of all, we address participants from various organizations in different industries and sizes. Our ambition is to reach a broad cross-section of organizations to compare the impact of different cultural types on the implementation of idea platforms between these organizations. Secondly, we restricted the job profiles during our search for participants. Following Ruppel and Harrington [41], IT managers are argued to be an appropriate source of evaluation of the overall culture and the extent of IT implementation. Since our focus is on the implementation of idea platforms, we filtered for IT managers as well as managers working in the area of innovation. We believe they are best placed to assess the company's innovation process and tools because they shape it or are at least directly involved in it. Before we sent the survey by e-mail, we tested the survey in a pre-test with five other researchers as well as two external managers in the field of innovation management. After our test and revision, we sent e-mails to our recipient list, introducing the project. The participants were informed which profile they should bring along so that they fit as a participant. We distributed the online survey to participants during August and November 2019. Our participant profiles in Table 1 shows that our participant selection was successful and matches our participant profile. 
At the very beginning of the online survey, we informed the participants on the welcome page that there are no wrong answers, that they should answer honestly, and we ensured that all answers are processed anonymously. In addition, we have included information on processing time, target group specifications, and the topic without mentioning the term idea platforms. This was done to avoid the participants to be subject of a common method bias as well as a social desirability bias [52, 53].

Table 1. Profiles of responding organizations and individuals $(\mathrm{N}=81)$

\begin{tabular}{|c|c|c|c|c|c|c|c|}
\hline \multicolumn{4}{|c|}{ Organization profiles } & \multicolumn{4}{|c|}{ Individual profiles } \\
\hline $\begin{array}{l}\text { Business area } \\
\text { (multiple selection } \\
\text { possible) }\end{array}$ & $\%$ & $\begin{array}{l}\text { Organization } \\
\text { size } \\
\text { (in persons) }\end{array}$ & $\%$ & $\begin{array}{c}\text { Professional } \\
\text { field of } \\
\text { activity }\end{array}$ & $\%$ & $\begin{array}{l}\text { Management } \\
\text { Responsibility }\end{array}$ & $\%$ \\
\hline Chemistry / Pharma & 24,7 & less than 10 & 2,5 & Communication & 1,2 & \multirow{3}{*}{$\begin{array}{l}\text { Management level } \\
\text { (no staff } \\
\text { responsibility) }\end{array}$} & \multirow{3}{*}{19,8} \\
\hline Communication & 3,7 & 10 to 49 & 6,2 & $\begin{array}{l}\text { Finance \& } \\
\text { Controlling }\end{array}$ & 1,2 & & \\
\hline $\begin{array}{l}\text { Consumer goods (e.g., } \\
\text { food) }\end{array}$ & 4,9 & 50 to 249 & 8,6 & Human resources & 1,2 & & \\
\hline Electrics / Electronics & 9,9 & 250 to 499 & 25,9 & IT & 43,2 & \multirow{3}{*}{$\begin{array}{l}\text { Lower } \\
\text { management level } \\
\text { (e.g., team leader, } \\
\text { group leader) }\end{array}$} & \multirow{3}{*}{14,8} \\
\hline Finance / Insurance & 13,6 & 500 to 999 & 34,6 & $\begin{array}{l}\text { Manufacturing \& } \\
\text { Production }\end{array}$ & 0 & & \\
\hline Human health & 11,1 & 1,000 to 4,999 & 8,6 & Marketing & 3,7 & & \\
\hline IT & 19,8 & 5,000 to 19,999 & 7,4 & Purchase \& Sales & 1,2 & \multirow{3}{*}{$\begin{array}{l}\text { Middle } \\
\text { management } \\
\text { (e.g., department-, } \\
\text { division heads) }\end{array}$} & \multirow{3}{*}{42,0} \\
\hline $\begin{array}{l}\text { Mechanical } \\
\text { engineering }\end{array}$ & 8,6 & 20,000 to 99,999 & 1,2 & $\begin{array}{l}\text { Research \& } \\
\text { Development }\end{array}$ & 25,9 & & \\
\hline Service & 7,4 & 100,000 or more & 4,9 & Other activity & 22,2 & & \\
\hline Transport & 1,2 & & & & & \multirow{3}{*}{$\begin{array}{l}\text { Upper } \\
\text { management level } \\
\text { (e.g., executive } \\
\text { board) }\end{array}$} & \multirow{3}{*}{23,5} \\
\hline Vehicle construction & 2,5 & & & & & & \\
\hline Others & 25,9 & & & & & & \\
\hline
\end{tabular}

We adapted the items (including reverse items) and overall questionnaire structure from Ruppel and Harrington [41] to measure the OC. The construct name/culture type was not mentioned to avoid influencing the respondents. Since the questions have already proven to be reliable, we did not expect a ceiling or floor effect for the items. We furthermore included an attention check [54]. All OC items were measured using a five-point Likert scale. After the questionnaire part on OC, we provided our definition of idea platforms to create a common understanding of the following questions. When asked about the progress of the introduction of an idea platform, the participant could select between the following options: "An idea platform: (a) has not yet been relevant and is, therefore, not in use (b) was evaluated, but we consciously decided against a deployment at this point (c) is being planned and evaluated (d) is currently being introduced (e) is in use (f) was used and abolished again".

Later, we grouped the options a), b) \& f) as (1) "no use", options c) \& d) as (2) "planning" and option e) as (3) "in use". This categorical measure is preferable to a dichotomous use/non-use variable. It allows the variables to be analyzed in terms of the progress of the idea platform implementation [41].

Since there are not many comparable studies on the implementation of idea platforms focusing on the software component, we surveyed additional variables on the 
actual or planned design of idea platforms. For group (1) "no use", we asked for reasons for the decision against the implementation of an idea platform as an open question, as well as whether the participant was involved in the decision. For group (2) "planning" and (3) "in use", we surveyed the type of use, the associated objectives, and the frequency of use. The questions of group (3) correspond in content to the questions of group (2) and differ only in the tense of the question. These additional measurement instruments were developed by us for this study. We validated these questions with two experts in the field of consulting and software solutions for idea and innovation management solutions.

\subsection{Data Analysis}

We used SmartPLS software (v.3.2.8) for structural equation modeling and analysis of the organizational culture constructs as well as idea platform implementation. This software was also used together with the bootstrap resampling method to determine the significance of the paths within the structural model. This method is especially appropriate to handle small sample sizes [55].

Table 2. Cronbach's $\alpha$, Composite Reliability, AVE, HTMT (*single item constructs)

\begin{tabular}{|l|l|l|l|l|l|l|l|l|l|}
\hline Construct & \multicolumn{6}{l|}{ Reliability and Validity } & \multicolumn{3}{l|}{ Heterotrait-Monotrait Ratio (HTMT) of Correlations } \\
\hline & Cr. $\alpha$ & CR & AVE & DC & EC & GC & HC & IIP & RC \\
\hline Develop. Culture (DC) & 0.810 & 0.884 & 0.795 & & & & & & \\
\hline Ethical Culture (EC) & 0.701 & 0.818 & 0.603 & 0.446 & & & & & \\
\hline Group Culture (GC) & 0.660 & 0.823 & 0.705 & 0.662 & 0.651 & & & & \\
\hline Hierarch Culture (HC) & 0.731 & 0.875 & 0.779 & 0.191 & 0.212 & 0.249 & & & \\
\hline Implementation (IIP)* & $1.00^{*}$ & $1.00^{*}$ & 1.000 & 0.124 & 0.135 & 0.214 & 0.320 & & \\
\hline Rational Culture (RC) & 0.667 & 0.821 & 0.607 & 0.362 & 0.480 & 0.537 & 0.136 & 0.062 & \\
\hline Company Size (CS)* & $1.00^{*}$ & $1.00^{*}$ & 1.000 & 0.018 & 0.082 & 0.113 & 0.168 & 0.267 & 0.089 \\
\hline
\end{tabular}

Before running the analysis in SmartPLS, we inverted the reversed items and removed 7 participants who did not pass our attention check. Furthermore, we searched for straight-liner and racer in our data, which did not appear. The remaining sample size was 81. Then, we performed a Partial Least Squares Regression (PLS Regression). Factor analysis following the procedure of Hair Jr et al. (2016) led to the removal of two items: one from rational culture and one from ethical culture. Afterward, we successfully checked the loading of each item on the respective construct, which needs to be greater than the cross-loadings to all other constructs [56], which could be confirmed. The reliabilities of measures were tested using Cronbach's $\alpha$, Composite Reliability (CR), AVE and, HTMT, as shown in Table 2. All Cr. $\alpha$ values are above 0.6 as a threshold for internal consistency reliability. Furthermore, AVE values are above 0.5 and CR values above 0,8 [55]. Since the Fornell-Larcker criterion is considered less reliable for discriminant validity in variance-based structural equation models [57], 
such as the present one, the HTMT was used and showed good results with all values below the more conservative threshold of 0.85 . Therefore, we can assume that the resulting measures had good internal reliability and validity. Lastly, we tested for multicollinearity between the constructs by calculating the related variance inflation factors (VIF). With a maximum VIF of 1.754, all values are well below the cutoff criterion of 5 [55].

Next, we analyzed our additional variables for the actual or planned design of idea platforms. Thereby, we mainly carried out group comparisons between the two groups (2) "planning" and (3) "in use". First, we isolated the data of the two groups from the first group. When capturing the type of implementation and objectives of the platform through our items, we allowed clicking the option "I can't judge". The removal of incomplete data records brought us to a sample size of 45 for our group comparison. This was to ensure that only participants who were able to assess the design criteria of the idea platform were evaluated.

To test if the proportions in group 2 and group 3 are not equal $\left(\mathrm{H}_{0}: \mathrm{P}_{1}=\mathrm{P}_{2}\right)$, we used the chi-square test of homogeneity [58]. Therefore, we reviewed four assumptions that are necessary to perform this test. First, our independent variable group was measured at the dichotomous level. All other dependent variables, which were tested individually, were also dichotomous variables. Second, by having different participants in each group, we could confirm that our observations have independence, which means there is no relationship between the observations in each group or between the groups themselves. Third, in our study design, we did purposive sampling through the characteristic of implementation of an idea platform. Lastly, our minimum sample size was greater than five for each expected frequency [59]. We were able to confirm all the requirements for this test.

\section{$4 \quad$ Results}

Our analysis was performed by a bootstrapping algorithm with 5,000 subsamples within SmartPLS software. In total, $21,3 \%$ of the variance in idea platform implementation is explained by the organizational culture and company size $(\mathrm{R}$ square $=0.213$ ).

Only hypothesis $\mathrm{H} 2$ of the OC dimensions was supported since there is no significant relationship between a rational culture and idea platform implementation. Surprisingly, we found a positive correlation between the hierarchical culture orientation and idea platform implementation: the more hierarchical a culture is perceived, the more likely an idea platform is implemented $\left(\mathrm{p}=0.004, \mathrm{f}^{2}=0,107\right)$. The $\mathrm{f}^{2}$ effect size can be interpreted as a small to medium effect size [55].

The group culture $\left(\mathrm{p}=0.089, \mathrm{f}^{2}=0.055\right)$ had a weak $\mathrm{f}^{2}$ effect size and was not significant at a significance level of $5 \%$. It was, however, marginally significant ( $\mathrm{p}$ 0.1 ), which is worth mentioning due to an explorative character of the study, where a significant level of $10 \%$ is often assumed in research [55]. The other cultures did not exhibit any significant association with idea platform. 
Lastly, H6 could be confirmed $\left(\mathrm{p}=0.013, \mathrm{f}^{2}=0,069\right)$, having a weak $\mathrm{f}^{2}$ effect size. Thereby, it could be confirmed that the company size has a significant positive influence on the introduction of an idea platform.

In the second part of the study, we analyzed whether the two groups (2) 'in planning' and (3) 'in use' pursue different objectives when implementing idea platforms. For this purpose, we defined seven objectives in advance, referred to as O1-O7, which are described in this section, along with their results. The difference between the two implementation groups was not statistically significant $(\mathrm{p}>.05)$ for the following objectives: 'Finding ideas for new innovations in the core business (O2)', 'Finding ideas for new innovations in new business areas $(\mathbf{O 3})$ ', 'Creating knowledge exchange, communication and awareness for strategic topics (O4)' and 'Building an innovation culture (O7)'. Therefore, we fail to reject the null hypothesis $\left(\mathrm{H}_{0}: \mathrm{P}_{1}=\mathrm{P}_{2}\right)$ and can assume that there are non-statistically significant differences in proportions.

The two goals 'Continuous improvement of business processes (O1)' and 'Search for solutions to known and concrete problems (problem-oriented) (O6)' were statistically significantly different $(\mathrm{p}<.05)$. Fourteen participants $(73,7 \%)$ plan to implement problem-oriented initiatives on the idea platform compared to 10 participants $(38,5 \%)$ who actually implement problem-oriented initiatives, a statistically significant difference in proportions of $.352, p=.019$. Even greater is the difference with 'Continuous improvement of business processes'. Here, 7 participants $(36,8 \%)$ plan to implement idea platforms for continuous improvement compared to 21 participants $(80,8 \%)$, a statistically significant difference in proportions of $.44, p=.003$.

Less strong is the difference with 'Breaking down silos and bringing together employees from different expertise and functions (O5)'. Here, 12 participants $(63,2 \%)$ planned to explicitly pursue this goal with the implementation of the idea platform compared to 9 participants $(34,6 \%)$ who actually pursue this goal with the deployment, a difference in proportions of $.286, \mathrm{p}=.058$.

Furthermore, we also used the test of two proportions to analyze the differences between three different usage types: 'submit ideas on any topic at any time', 'participate in targeted and time-limited campaigns of a specific user group', and 'take part in company-wide idea challenges'. None of the differences were significant. Besides, none of the other control variables were significant.

\section{Discussion}

Commencing with the theoretical implications, the results of our study confirm that the $\mathrm{OC}$ as a whole influence the current status of idea platform implementation. Our analysis shows that $15.9 \%$ of the implementation status can be attributed to the organizational culture (21.3\%, including company size). Hence we can conclude that idea platforms are not only used to transform OC [30] but that a corresponding OC makes the implementation of idea platforms more likely. Thereby, we contribute to the research stream 'Culture, IT Adoption, and Diffusion' [39]. Against our assumption, we show that idea platform implementation is facilitated by a hierarchical culture that emphasizes policies, procedures, and information management. A possible explanation 
for this could be that internal idea competitions harmonize better with the internal focus of the hierarchical culture than, e.g., an open innovation platform would have done. Idea platforms, as software tools, can support to structure their ideation process [44] and, thus, the management in its efforts for internal order. This effect is reinforced by the fact that a large proportion of idea platforms are used to collect continuous improvements in operational improvement, which is characterized by a very formal and regulated process. The results also show that a stronger group culture has a (marginally significant) positive effect on the level of idea platform implementation, as hypothesized. Organizations fostering a group culture emphasize employee involvement, which may be realized through idea platforms [45]. Alongside employee participation the group culture also embraces personal dialogue [41]. When managers promote ideation techniques through dialogue, this may weaken the additional benefit from idea competitions for them and, thus, limiting the significant influence in our model. Next, as hypothesized, a stronger rational culture was not related to idea platform implementation. Organizations with a rational culture may be familiar with idea platforms and their potential for open innovation through their external focus but have no preference for or against their use. The benefit of using idea platforms is not only derived from the ideas themselves. Other advantages can arise, such as the identification of key individuals, which is also interesting from the point of view of the promoter theory in innovation management [60]. However, these kinds of advantages are usually difficult to measure, which is not in line with a strong rational culture since it values objective-based measures. If crowdsourced and open innovation can provide more objective measures in the future, we imagine that a rational culture will have a positive impact on the implementation of idea platforms. Then, there was no positive correlation between development culture and the implementation of an idea platform. Organizations with a development culture are focused on growth and innovation. However, it does not appear that idea platforms are currently used in practice to promote innovation nor open innovation. Lastly, our hypothesis about a positive correlation between ethical culture and the implementation of idea platforms could not be confirmed either. Our survey measures on objectives indicate that using an idea platform to facilitate knowledge exchange is the least pursued objective between our participants. Against this background, ethical culture may have less influence on the design of the platform in terms of knowledge exchange.

Overall, we believe that the significant relationship between organizations with a strong group and hierarchical cultures and idea platforms can be explained by the way the idea platform is designed. In the past, idea platforms were initially intended for internal use. This internal focus was also shaped by the culture in which idea platforms were used since both significant cultures share this orientation in the CVF. In recent years, organizations have begun to open up their innovation processes and diffuse them more widely [4]. However, especially in B2B [6], idea platforms that open up to involve larger crowds may not encounter a culture that promotes innovation and creativity and therefore may not achieve active participation or expected results [16]. This fact reinforces the current discussion about the uncertain overall value of crowdsourced ideation initiatives [31]. 
Moving beyond theoretical implications, our study also has practical implications for idea platform provider, innovation managers, and organizations implementing idea platforms. Our study highlights the importance of taking OC into account when introducing a new technology or process that may be incompatible with the existing culture. Our analysis of planned versus the actual implementation objectives further indicates that idea platform usage will shift towards crowdsourced idea generation with a higher degree of innovation (e.g., less continuous improvement and more problemoriented usage). Furthermore, culture also influences the design of idea platforms as well as the adoption and influence of IT Tools [39], as with idea platforms. As a result, organizations must be aware of their existing organizational culture when implementing and designing idea platforms to meet their expectations. Adoption is more likely when the values of a group match the values of information technology [39] as well as the design of idea platform needs to be in line with complementary factors of strategy and structure [17].

\section{$6 \quad$ Limitations and Future Research}

Certainly, this study also has its limitations. First, we only used a 5-step Likert scale in order not to overwhelm the respondents. In combination with the low number of items per construct, the lower gradation leads to a worse differentiation of persons, organizations, and cultures. The significance of the results is, therefore, weakened. Furthermore, we sent the survey to unknown contacts and busy managers. This resulted in a low response rate (around 8\%). Because of this, the generalizability of these findings is somewhat in question. Since we defined idea platforms very broadly in our study, we have not been able to measure the impact of culture on specific deployment forms. However, this was not intended and opens up the field for further research.

Further research could focus on specific applications of idea platforms as open innovation, specific idea competition formats, or similar. It is particularly interesting to see whether an OC that promotes the implementation of idea platforms also increases their chances of success and user satisfaction. Moreover, it would be particularly relevant in practice to know whether OC can also provide negative effects. This would enable organizations to decide more quickly whether i.e. idea competitions are a suitable method for them.

Further research is necessary to see the influence of the idea platform on the culture. In particular, we could imagine that certain designs of idea platforms could even reinforce some cultures. Next, further research is needed to identify the advantages and role of an idea platform as a digital platform. The influence of the properties of digital goods, in particular network effects, on idea platforms can be investigated. Finally, more research is required to explore the advantages of idea platforms, taking into account the promoter theory, in connection with areas of social network analysis, the identification of key persons for the success of idea platforms, and innovation in general. 


\section{References}

1. Kohli, R., Melville, N.P.: Digital innovation: A review and synthesis. Information Systems Journal 29, 200-223 (2019)

2. Gregory, R., Wagner, H.-T., Tumbas, S., Drechsler, K.: At the Crossroads between Digital Innovation and Digital Transformation. ICIS 2019 Proceedings (2019)

3. Bogers, M., West, J.: Managing Distributed Innovation: Strategic Utilization of Open and User Innovation. Creativity and Innovation Management 21, 61-75 (2012)

4. Ili, S., Albers, A., Miller, S.: Open innovation in the automotive industry. R\&D Management 40, 246-255 (2010)

5. Zuchowski, O., Posegga, O., Schlagwein, D., Fischbach, K.: Internal Crowdsourcing: Conceptual Framework, Structured Review, and Research Agenda. Journal of Information Technology 31, 166-184 (2016)

6. Simula, H., Vuori, M.: Benefits and barriers of crowdsourcing in B2B firms: Generating ideas with internal and external crowds. International Journal of Innovation Management $16,1240011(2012)$

7. Yoo, Y., Boland, R.J., Lyytinen, K., Majchrzak, A.: Organizing for Innovation in the Digitized World. Organization Science 23, 1398-1408 (2012)

8. Surowiecki, J.: The wisdom of crowds: Why the many are smarter than the few and how collective wisdom shapes business, economies, societies, and nations. Doubleday, New York, NY (2004)

9. Majchrzak, A., Malhotra, A.: Towards an information systems perspective and research agenda on crowdsourcing for innovation. The Journal of Strategic Information Systems 22, 257-268 (2013)

10. Nov, O.: What motivates Wikipedians? Communications of the ACM 50, 60-64 (2007)

11. Wasko, M.M., Faraj, S.: Why Should I Share?: Examining Social Capital and Knowledge Contribution in Electronic Networks of Practice. MIS Quarterly 29, 35-57 (2005)

12. Poetz, M.K., Schreier, M.: The Value of Crowdsourcing: Can Users Really Compete with Professionals in Generating New Product Ideas? J Prod Innovat Manag 29, 245-256 (2012)

13. Schemmann, B., Herrmann, A.M., Chappin, M.M.H., Heimeriks, G.J.: Crowdsourcing ideas: Involving ordinary users in the ideation phase of new product development. Research Policy 45, 1145-1154 (2016)

14. Bullinger, A.C., Möslein, K.M.: Innovation contests-where are we? AMCIS, pp. 28-35 (2010)

15. Zhu, H., Kock, A., Wentker, M., Leker, J.: How Does Online Interaction Affect Idea Quality?: The Effect of Feedback in Firm-Internal Idea Competitions. J Prod Innovat Manag 36, 24-40 (2019)

16. Leimeister, J.M., Huber, M., Bretschneider, U., Krcmar, H.: Leveraging Crowdsourcing: Activation-Supporting Components for IT-Based Ideas Competition. J Manage Inform Syst 26, 197-224 (2014)

17. Kohli, R., Grover, V.: Business Value of IT: An Essay on Expanding Research Directions to Keep up with the Times. J Assoc Inf Syst 9, 23-39 (2008)

18. Hutter, K., Hautz, J., Füller, J., Mueller, J., Matzler, K.: Communitition: The Tension between Competition and Collaboration in Community-Based Design Contests. Creativity and Innovation Management 20, 3-21 (2011)

19. Denison, D.R., Spreitzer, G.M., others: Organizational culture and organizational development: A competing values approach. Research in organizational change and development 5, 1-21 (1991) 
20. Quinn, R.E., Rohrbaugh, J.: A Spatial Model of Effectiveness Criteria: Towards a Competing Values Approach to Organizational Analysis. Management Science 29, 363-377 (1983)

21. Iivari, J., Huisman, M.: The Relationship between Organizational Culture and the Deployment of Systems Development Methodologies. MIS Quarterly 31, 35-58 (2007)

22. McDermott, C.M., Stock, G.N.: Organizational culture and advanced manufacturing technology implementation. J Oper Manag 17, 521-533 (1999)

23. Malhotra, M.K., Grover, V.: An assessment of survey research in POM: from constructs to theory. J Oper Manag 16, 407-425 (1998)

24. van den Ende, J., Frederiksen, L., Prencipe, A.: The Front End of Innovation: Organizing Search for Ideas. J Prod Innovat Manag 32, 482-487 (2015)

25. Birkinshaw, J., Gibson, C.B.: Building Ambidexterity Into an Organization. MIT Sloan management review 47-55 (2004)

26. Chesbrough, H.W.: Open innovation: The new imperative for creating and profiting from technology. Harvard Business Press (2003)

27. Afuah, A., Tucci, C.L.: Crowdsourcing As a Solution to Distant Search. Academy of Management Review 37, 355-375 (2012)

28. Allen, B.J., Chandrasekaran, D., Basuroy, S.: Design Crowdsourcing: The Impact on New Product Performance of Sourcing Design Solutions from the "Crowd". J Marketing 82, 106123 (2018)

29. West, J., Bogers, M.: Leveraging External Sources of Innovation: A Review of Research on Open Innovation. J Prod Innovat Manag 31, 814-831 (2014)

30. Ebner, W., Leimeister, J.M., Krcmar, H.: Community engineering for innovations: The ideas competition as a method to nurture a virtual community for innovations. R\&D Management 39, 342-356 (2009)

31. Mortara, L., Ford, S.J., Jaeger, M.: Idea Competitions under scrutiny: Acquisition, intelligence or public relations mechanism? Technological Forecasting and Social Change 80, 1563-1578 (2013)

32. Hofstede, G., Hofstede, G.J.: Cultures and organizations: Software of the mind: Intercultural cooperation and its importance for survival. McGraw-Hill, New York (2005)

33. Schein, E.H.: Organizational culture. American Psychological Association 45, 109-119 (1990)

34. Kirkman, B.L., Shapiro, D.L.: The Impact of Cultural Values on Job Satisfaction and Organizational Commitment in Self-Managing Work Teams: The Mediating Role of Employee Resistance. Academy of Management Journal 44, 557-569 (2001)

35. Naranjo-Valencia, J.C., Jiménez-Jiménez, D., Sanz-Valle, R.: Innovation or imitation?: The role of organizational culture. Management Decision 49, 55-72 (2011)

36. Narver, J.C., Slater, S.F.: The Effect of a Market Orientation on Business Profitability. J Marketing 54, 20-35 (1990)

37. Hauschildt, J., Kock, A., Salomo, S., Schultz, C.: Innovationsmanagement. Verlag Franz Vahlen, München (2016)

38. Grote, M., Herstatt, C., Gemünden, H.G.: Cross-Divisional Innovation in the Large Corporation: Thoughts and Evidence on Its Value and the Role of the Early Stages of Innovation. Creativity and Innovation Management 21, 361-375 (2012)

39. Leidner, D.E., Kayworth, T.: Review: A Review of Culture in Information Systems Research: Toward a Theory of Information Technology Culture Conflict. MIS Quarterly 30, 357-399 (2006) 
40. Coombs, R., Knights, D., Willmott, H.C.: Culture, Control and Competition; Towards a Conceptual Framework for the Study of Information Technology in Organizations. Organization Studies 13, 051-072 (2016)

41. Ruppel, C.P., Harrington, S.J.: Sharing knowledge through intranets: A study of organizational culture and intranet implementation. IEEE Transactions on Professional Communication 44, 37-52 (2001)

42. Cooper, R.B.: The inertial impact of culture on IT implementation. Information \& Management 27, 17-31 (1994)

43. Cooper, R.B., Quinn, R.E.: Implications of the competing values framework for management information systems. Human Resource Management 32, 175-201 (1993)

44. Elerud-Tryde, A., Hooge, S.: Beyond the Generation of Ideas: Virtual Idea Campaigns to Spur Creativity and Innovation. Creativity and Innovation Management 23, 290-302 (2014)

45. Björk, J., Magnusson, M.: Where Do Good Innovation Ideas Come From?: Exploring the Influence of Network Connectivity on Innovation Idea Quality. J Prod Innovat Manag 26, 662-670 (2009)

46. Blohm, I., Bretschneider, U., Leimeister, J.M., Krcmar, H.: Does collaboration among participants lead to better ideas in IT-based idea competitions?: An empirical investigation. International Journal of Networking and Virtual Organisations 9, 106-122 (2011)

47. Björk, J., Di Vincenzo, F., Magnusson, M., Mascia, D.: The Impact of Social Capital on Ideation. Industry \& Innovation 18, 631-647 (2011)

48. Brown, R.B., Woodland, M.J.: Managing Knowledge Wisely: A case study in organisational behaviour. Journal of Applied Management Studies 8, 175-198 (1999)

49. Curry, A., Stancich, L.: The intranet - an intrinsic component of strategic information management? International Journal of Information Management 20, 249-268 (2000)

50. Beretta, M., Björk, J., Magnusson, M.: Moderating Ideation in Web-Enabled Ideation Systems. J Prod Innovat Manag 35, 389-409 (2018)

51. Scholl, A.: Die Befragung. UVK Verlagsgesellschaft mbH UVK/ Lucius, Konstanz; München (2018)

52. Podsakoff, P.M., MacKenzie, S.B., Lee, J.-Y., Podsakoff, N.P.: Common method biases in behavioral research: A critical review of the literature and recommended remedies. The Journal of Applied Psychology 88, 879-903 (2003)

53. Mummendey, H.D., Grau, I.: Die Fragebogen-Methode: Grundlagen und Anwendung in Persönlichkeits-, Einstellungs-und Selbstkonzeptforschung. Hogrefe Verlag, Göttingen (2008)

54. Meade, A.W., Craig, S.B.: Identifying careless responses in survey data. Psychological methods 17, 437 (2012)

55. Hair Jr, J.F., Hult, G.T.M., Ringle, C., Sarstedt, M.: A primer on partial least squares structural equation modeling (PLS-SEM). Sage publications (2016)

56. Bagozzi, R.P., Yi, Y.: Specification, evaluation, and interpretation of structural equation models. J Acad Market Sci 40, 8-34 (2012)

57. Henseler, J., Ringle, C.M., Sarstedt, M.: A new criterion for assessing discriminant validity in variance-based structural equation modeling. J Acad Market Sci 43, 115-135 (2015)

58. Marascuilo, L.A., MacSweeney, M.: Nonparametric and distribution-free methods for the social sciences. Brooks/Cole, Monterey, Calif. (1977)

59. Hollander, M., Wolfe, D.A., Chicken, E.: Nonparametric statistical methods. John Wiley \& Sons (2013)

60. Witte, E.: Power and Innovation: A Two-Center Theory. International Studies of Management \& Organization 7, 47-70 (1977) 